J. Lake Sci. (湖泊科学), 2020, 32(4): 1008-1019

DOI 10. $18307 / 2020.0410$

(c) 2020 by Journal of Lake Sciences

\title{
土地利用结构与景观格局对鄱阳湖流域赣江水质的影响”
}

\author{
徐启渝 ${ }^{1,2}$, 王 鹏 ${ }^{1,2 * *}$, 王 涛 ${ }^{3}$,舒 旺 ${ }^{1,2}$, 张 华 ${ }^{1,2}$, 齐述华 ${ }^{1,2}$ \\ ( 1 : 江西师范大学地理与环境学院, 南昌 330022) \\ ( 2 : 江西师范大学鄱阳湖湿地与流域研究教育部重点实验室,南昌 330022) \\ (3: 贵州省测绘产品质量监督检查站, 贵阳 550054)
}

\begin{abstract}
摘 要: 于 2015 年 1 月和 7 月采集赣江干流及支流 34 个采样点水样,测定电导率、水化学离子、无机氮等水质指标. 利用 赣江流域 2014 年 $30 \mathrm{~m}$ 分辨率的土地利用数据, 以流域景观类型占比表征土地利用结构, 景观指数表征景观格局; 采用 Pearson 相关分析、Bioenv 分析、Mantle 检验与方差分解等方法分析流域土地利用结构与景观格局对赣江水质的影响. 结 果表明: 上游 $\mathrm{Cl}^{-} 、 \mathrm{Na}^{+}$浓度最高, 中游电导率、 $\mathrm{Cl}^{-} 、 \mathrm{Na}^{+} 、 \mathrm{~K}^{+} 、 \mathrm{Ca}^{2+}$ 等水质指标最低,下游电导率、 $\mathrm{HCO}_{3}^{-} 、 \mathrm{SO}_{4}^{2-} 、 \mathrm{Mg}^{2+} 、 \mathrm{Ca}^{2+} 、$ $\mathrm{NO}_{3}^{-}-\mathrm{N}$ 等水质指标最高. 居民建设用地是对水质影响最显著的单一土地利用类型. 林地、水田与居民建设用地是对水质 影响最显著的土地利用类型组合. 平均最近邻体指数是对水质影响最显著的单一景观指数, 斑块个数、斑块聚集度指数、 平均最近邻体指数是对水质影响最显著的景观指数组合. 枯水期土地利用结构和景观格局对水质的贡献率分别为 $41.1 \%$ 和 17.2\%,景观格局对水质的贡献率 (17.2\%) 均为和土地利用结构的交互作用, 无独立贡献部分;丰水期二者对水质贡献 率分别为 $51 \% 、 53 \%$,交互作用部分为 $37 \%$. 以上结果表明,土地利用结构与景观格局都对贑江水质有较大影响,二者的 交互作用在该影响中占有重要地位,且枯水期景观格局对水质的影响涵盖在与土地利用结构的交互作用中.
\end{abstract}

关键词: 赣江流域;土地利用;景观指数;水质;交互作用

\section{Investigation of the impacts of land use structure and landscape pattern on water quality in the Ganjiang River, Lake Poyang Basin*}

\author{
XU Qiyu ${ }^{1,2}$, WANG Peng ${ }^{1,2 * *}$, WANG Tao ${ }^{3}$, SHU Wang ${ }^{1,2}$, ZHANG Hua ${ }^{1,2}$ \& QI Shuhua ${ }^{1,2}$ \\ (1: School of Geography and Environment, Jiangxi Normal University, Nanchang 330022, P.R. China) \\ (2: Key Laboratory of Poyang Lake Wetland and Watershed Research, Ministry of Education, Jiangxi Normal University, Nan- \\ chang 330022, P.R. China) \\ (3: Guizhou Surveying and Mapping Product Quality Supervision and Inspection Station, Guiyang 550054, P.R.China)
}

Abstract: In this study, water samples were taken from 34 sampling points in the main stream and tributaries of the Ganjiang River in January and July 2015, and the water quality indicators such as electrical conductivity (EC), water chemical ions and the concentrations of inorganic nitrogen were determined. The land use structure in the Ganjiang River Basin was represented by landscape type ratios, and the landscape pattern was represented by landscape indexes, based on the $30 \mathrm{~m}$ resolution land use data. The Pearson correlation analysis, Bioenv analysis, Mantle test and variation partitioning analysis (VPA) were used to analyze the impacts of watershed land use structure and landscape pattern on the water quality of the Ganjiang River. The results showed that: (1) The concentrations of $\mathrm{Cl}^{-}$and $\mathrm{Na}^{+}$were the highest in the upstream, EC, concentrations of $\mathrm{Cl}^{-}, \mathrm{Na}^{+}, \mathrm{K}^{+}$and $\mathrm{Ca}^{2+}$ were the lowest in the middle stream, and $\mathrm{EC}$, concentrations of $\mathrm{HCO}_{3}^{-}, \mathrm{SO}_{4}^{2-}, \mathrm{Mg}^{2+}, \mathrm{Ca}^{2+}$ and $\mathrm{NO}_{3}^{-}-\mathrm{N}$ were the highest in the downstream. (2) The construction land was the individual land use type that best explained the variations in water quality. Forest land, paddy fields and construction land were the subset of land use types that best explained the variations in water quality. (3) The $E N N \_M N$ index was the individual landscape index that best explained the variations in water quality. $N P, C O H E S$ and $E N N \_M N$ were the subset

* 2019-09-13 收稿;2019-11-13 收修改稿.

国家自然科学基金项目 (41201033)、江西省重大生态安全问题监控协同创新中心项目 ( JX-EW-00) 和流域生态与 地理环境监测国家测绘地理信息局重点实验室开放基金项目 (WE2016017) 联合资助.

** 通信作者;E-mail: wangpengjlu@ jxnu.edu.cn. 
of landscape index that best explained the variations in water quality. (4) In the dry season, the land use structure and landscape pattern accounted for $41.1 \%$ and $17.2 \%$ of the variance in water quality, respectively; the effect of landscape pattern was totally interacted with land use structure, without an independent contribution. In the wet season, the land use structure and landscape pattern accounted for $51 \%$ and $53 \%$ of the variance in water quality, respectively; the interactive part was 37\% . Both land use structure and the landscape pattern have a great influence on water quality of Ganjiang River, and their interactive parts play an important role in this influence. The influence of landscape pattern on water quality in dry season was included in the interaction with land use structure.

Keywords: Ganjiang River Basin; land use structure; landscape index; water quality ; interaction

水资源是社会发展的必要资源, 过去 40 年间中国城市扩张、人口增长带来的水质恶化已成为当前生态 文明建设的主要限制因素 ${ }^{[1-2]}$, 人类活动改变了土地利用方式与自然景观格局, 是导致河流水质恶化的主要 原因 ${ }^{[3]}$. 土地利用结构侧重于组成单元的多样性, 景观格局侧重于空间构型特征, 而在当前研究中缺乏将二 者概念区分开进行研究 ${ }^{[4-5]}$,忽略了土地利用结构与景观格局存在的交互影响,在分析景观空间构型对水质 的作用中略显不足. 已有研究表明 ${ }^{[6]}$, 不同于土地利用结构, 景观格局侧重的斑块空间特征是景观时空异质 性的具体表现,其空间构型对流域内水文循环过程起到了关键作用. 因此,本文选取土地利用结构表征土地 利用, 各类景观指数表征景观格局, 明确二者之间的交互作用与独立作用分别对水质的贡献率, 为恢复河流 水质保障社会发展用水提供科学的理论基础.

土地利用结构与景观格局对水质的影响是通过在不同空间尺度上, 人工景观如农田、建设用地等取代 了自然景观林地、草地等, 导致“源” “汇” 景观比例失衡, 空间配置变化并最终造成了水质恶化的环境负效 应 $^{[7-9]}$, 为此, 探索土地利用结构、景观格局与水质间的联系是保护水质的重要前提, 然而土地利用类型多 样,景观指数种类丰富, 指标之间还存在信息冗余, 如何选出少量的关键性指标, 建立土地利用结构、景观格 局与水质间的联系,并分析其影响机理, 是此类研究的难点 ${ }^{[10-11]}$. 传统分析方法发现土地利用类型中城镇用 地、林地、耕地、草地与水质相关性最高, 景观格局特征中, 破碎度、聚集度、物理连接度以及多样性特征与水 质显著相关 ${ }^{[11-14]}$. 这些研究尽管能够得到某种土地利用方式或景观格局特征与水质的相关性,但无法处理 多变量多重共线性问题,不能明确土地利用结构或景观格局对水质变化贡献率的大小. 为此, 崔丹等 ${ }^{[15]}$ 通 过构建结构方程模型建立变量间的因果关系, 对土地利用结构、景观格局与水质间的复杂关系进行模拟分 析, 发现城市、林地、连通性指数 (CONTAG)、聚集度指数 $(C O H E S)$ 的组合对水环境质量的贡献率最高. 然而 结构方程模型通过因子得分为潜变量赋值, 人为曲解了潜变量的取值及其变数 ${ }^{[16]}$, 不利于后续深人研究. 如何准确获取土地利用结构与景观格局对水质的贡献率, 并分析二者之间交互作用对水质的影响, 已成为 当前国内外研究热点 ${ }^{[17-18]}$.

赣江作为鄱阳湖第一大支流,年径流量 638 亿 $\mathrm{m}^{3}$, 约占鄱阳湖总径流量的 $46.6 \%$, 人湖水质优劣对鄱阳 湖整体水环境影响显著. 研究赣江流域水质变化对保护 “一湖清水”、保障鄱阳湖生态经济区的可持续发展 具有重要意义 ${ }^{[19]}$. 目前, 已有学者对赣江流域土地利用 ${ }^{[20-21]}$ 、温度降水 ${ }^{[22]}$ 等与水质的关系展开研究, 而对景 观格局与水质间的关系研究尚少. 因此本文基于环境变量的最佳组合,选取冗余信息最少的指标组合分别 表征土地利用与景观格局. 通过分解不同变量的贡献率, 定量评估二者对水环境质量的贡献, 并探讨贑江流 域土地利用结构与景观格局交互作用对水质的影响, 以揭示影响赣江流域水质变化的主要土地利用类型和 景观特征, 为流域水质保护提供科学参考.

\section{1 材料与方法}

\section{1 研究区概况与数据采集}

赣江是长江中下游的主要支流, 位于亚热带湿润季风气候区, 多年平均降水量约为 $1600 \mathrm{~mm}$, 时空分布 不均, $5-7$ 月占全年雨量比重最大,约占 $45.6 \%, 11-1$ 月 (次年) 降雨量最小,约占 $16.8 \%^{[1]}$. 赣江分四支注 人鄱阳湖, 干流长 $766 \mathrm{~km}$. 赣州市以上为上游 $(\mathrm{S} 1 \sim \mathrm{S} 3)$, 长 $255 \mathrm{~km}$; 赣州市至新干县城为中游 ( $\mathrm{S} 4 \sim \mathrm{S} 7)$, 长 $303 \mathrm{~km}$; 新干县城至吴城县城为下游 $(\mathrm{S} 8 \sim \mathrm{S} 9)$, 长 $208 \mathrm{~km}$.

本研究在赣江干流和支流设置 34 个采样点 (图 1, G 表示干流, Z 表示支流). 分别在 2015 年的 1 月 (枯 


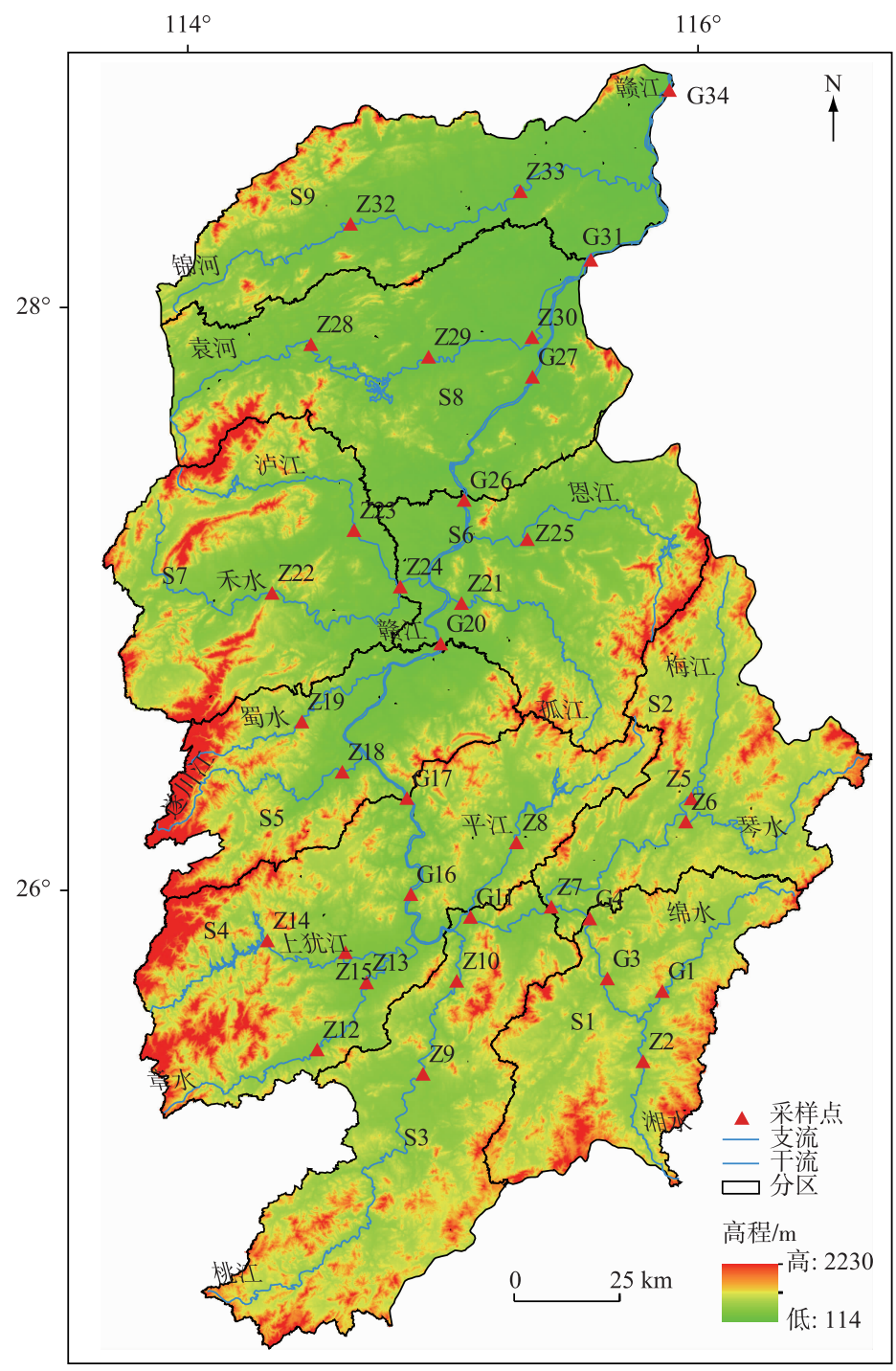

图 1 研究区区域划分及采样点分布

Fig. 1 Regional division of the study area and distribution of sampling sites

水期) 与 7 月 (丰水期) 采样, 水样在河中心 $50 \mathrm{~cm}$ 深度处提取, 利用便携式水质分析仪 (HI9828, HANNA, Italy) 现场测定电导率( EC) ; 通过 $0.45 \mu \mathrm{m}$ 孔径的醋酸纤维滤膜过滤, 装人取样瓶密封, 在 $0 \sim 4^{\circ} \mathrm{C}$ 下冷藏, 密 封保存. 氨氮 $\left(\mathrm{NH}_{3}-\mathrm{N}\right)$ 浓度采用纳氏试剂分光光度法测定, 硝酸盐氮 $\left(\mathrm{NO}_{3}^{-}-\mathrm{N}\right)$ 浓度采用酚二磺酸分光光度 法测定. $\mathrm{Na}^{+} 、 \mathrm{~K}^{+} 、 \mathrm{Mg}^{2+} 、 \mathrm{Ca}^{2+}$ 浓度采用等离子体发射光谱仪 (Optima 8000, PerkinElmer, USA) 测定; $\mathrm{Cl}^{-} 、 \mathrm{SO}_{4}^{2-}$ 浓 度采用离子色谱仪 ( ICP-90, Dionex, USA) 测定, 采样当天采用 $\mathrm{HCl}$ 滴定法测定 $\mathrm{HCO}_{3}^{-}$.

赣江流域土地利用数据来自中国科学院资源环境科学数据中心 2015 年 $30 \mathrm{~m} \times 30 \mathrm{~m}$ 精度的全国土地 利用遥感监测数据. 参照《环境状况评价技术规范》 ( HJ/T 192-2006) 中土地分类方法, 将研究区分为水田 (paddy field)、旱地 (dry farm)、林地 (forestland)、草地 (grassland)、水域 (water area)、建设用地 (residential) 和未利用地 (unused) 7 种土地利用类型,其中未利用地占比平均不到 $0.4 \%$,后续分析中不予考虑.

\section{2 景观指数选取}

由于研究者针对不同研究区选取了不同景观指数进行分析, 造成了景观指数对河流水质影响的不确定 
性 ${ }^{[5]}$, 对深人探究景观格局对水质作用的机理带来困难, 因此规范指标的选取,挑选合理的指标表征景观格 局特征是此类研究发展的必然需求. 本文参考国内外已有研究 ${ }^{[23-25]}$ 从表征景观破碎度、聚集度、优势度、多 样性和物理连接度等景观指数中, 选取了如表 1 所示通用性较高的 8 个指数, 其中斑块个数 $(N P)$ 、斑块密度 $(P D)$ 、景观形状 $(L S I)$ 分别表示景观中斑块的数量、密度、形状,通常用来评估景观破碎化的程度; 聚集度 (CONTAG)、斑块结合度 $(C O H E S)$ 分别表示景观中同一类型斑块的聚集程度和给定阈值的斑块连接度; 最 大斑块 $(L P I)$ 表示景观中面积最大的斑块其面积占比程度, 用来形容流域内优势景观类型; 香农多样性 ( SH$D I)$ 、平均最近邻体距离 $\left(E N N \_M N\right)$ 分别表示流域内景观类型的丰富度以及同类型斑块之间的平均距离. 景 观指数由 ArcGIS 10.2 提取栅格地图,应用 Fragstats 4.0 软件在景观水平计算获得.

表 1 研究所选取景观指数*

Tab.1 Landscape index selected in this study

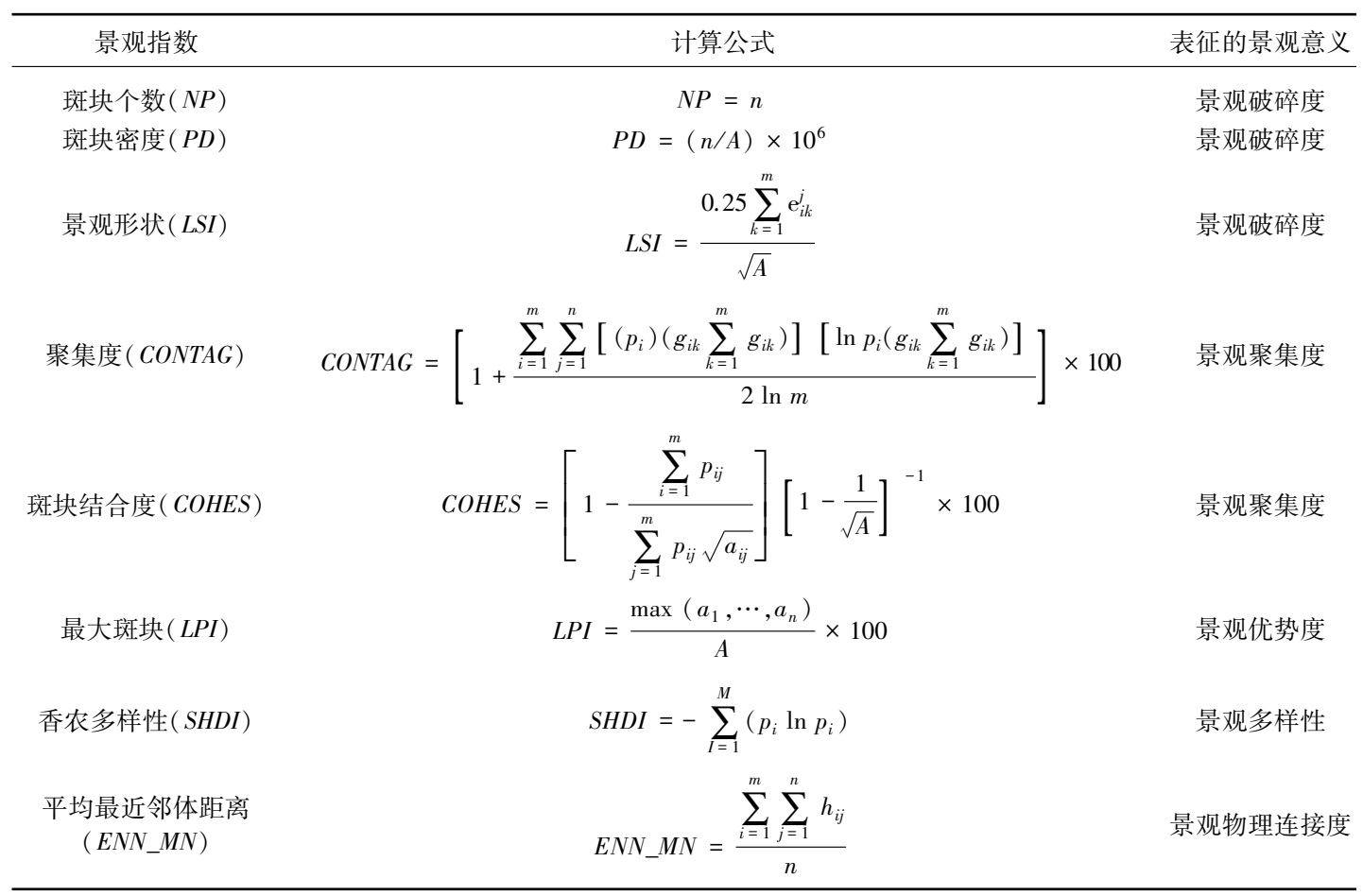

* 式中, $n$ 为斑块数目; $A$ 为景观总面积; $a_{1}, \cdots, a_{n}$ 为斑块的面积; $E$ 为景观中所有斑块边界的总长度; $p_{i g}$ 为斑块 $p_{i j}$ 的周 长; $p_{i}$ 为每一种斑块类型所占景观总面积的比例; $p_{k i}$ 为随机选择的 2 个相邻栅格细胞是属于类型 $k$ 与 $i$ 的概率; $m$ 为斑块 的类型总数; $n$ 为斑块总数.

\section{3 数据分析}

根据赣江流域水系实际分布状况, 从分水岭尺度将研究区聚类为 9 个区域 (图 1), 每个区域分布 $3 \sim 4$ 个采样点, 对同一区域内各采样点水质指标取平均值进行统计分析. 水质数据中超出平均值 \pm 3 倍标准差范 围的值作为异常值剔除, 采用 Shapiro-Wilk 检验数据正态性, $P>0.05$ 数据满足正态分布特征. 采用独立样本 $T$ 检验、Pearson 相关等方法分析水质指标在不同河段的差异, 以及水质指标与土地利用结构、景观格局间的 关系. 通过 R 语言“vegan”包中的“bioenv” 函数, 分别得到土地利用类型和景观指数的最佳组合, 并以此来 表征土地利用结构和景观格局. 通过 “Mantel” 检验控制土地利用类型和景观指数之间的相互影响后, 分析 二者与水质指标相关性的变化. 方差分解 (variation partitioning) 是将响应变量组成数据表的总方差无偏分 解成由各个解释变量所决定的子方差, 基于元余分析 ( RDA) 或约束分析 (CCA) 约束的特征值, 通过偏分析 计算解释变量对响应变量总方差的贡献率 ${ }^{[26-27]}$. 本研究利用 Canoco5 进行土地利用结构与景观格局对水质 变化的 RDA 分析与 $\mathrm{d}-\mathrm{RDA}$ 分析, 通过方差分解评估土地利用结构与景观格局对水质变化的独立贡献率和 
共同贡献率.

\section{2 结果}

\section{1 水质指标变化特征}

丰水期所有水质指标浓度显著低于枯水期 (图 2). 从 $T$ 检验结果 (表 2)中可以发现,在不同河段水质指 标浓度差异显著.上游 $\mathrm{Cl}^{-} 、 \mathrm{Na}^{+}$浓度最高, 中游 $\mathrm{EC} 、 \mathrm{Cl}^{-} 、 \mathrm{Na}^{+} 、 \mathrm{~K}^{+} 、 \mathrm{Ca}^{2+}$ 等水质指标浓度最低, 下游 $\mathrm{EC} 、 \mathrm{HCO}_{3}^{-}$、 $\mathrm{SO}_{4}^{2-} 、 \mathrm{Mg}^{2+} 、 \mathrm{Ca}^{2+} 、 \mathrm{NO}_{3}^{-}-\mathrm{N}$ 等水质指标浓度最高, 上游和中游河段水质指标差异性不显著, 中游到下游水质指 标大多发生显著性变化. 水体阳离子浓度 $\mathrm{Ca}^{2+}>\mathrm{Na}^{+}>\mathrm{K}^{+}>\mathrm{Mg}^{2+}$, 阴离子浓度 $\mathrm{HCO}_{3}^{-}>\mathrm{SO}_{4}^{2-}>\mathrm{Cl}^{-}$. $\mathrm{Z} 9$ 点多数 水质指标异常偏高, 超出平均值 \pm 3 倍标准差范围, 为避免异常值掩盖环境与水质间的内在联系, 在后续分 析中剔除.
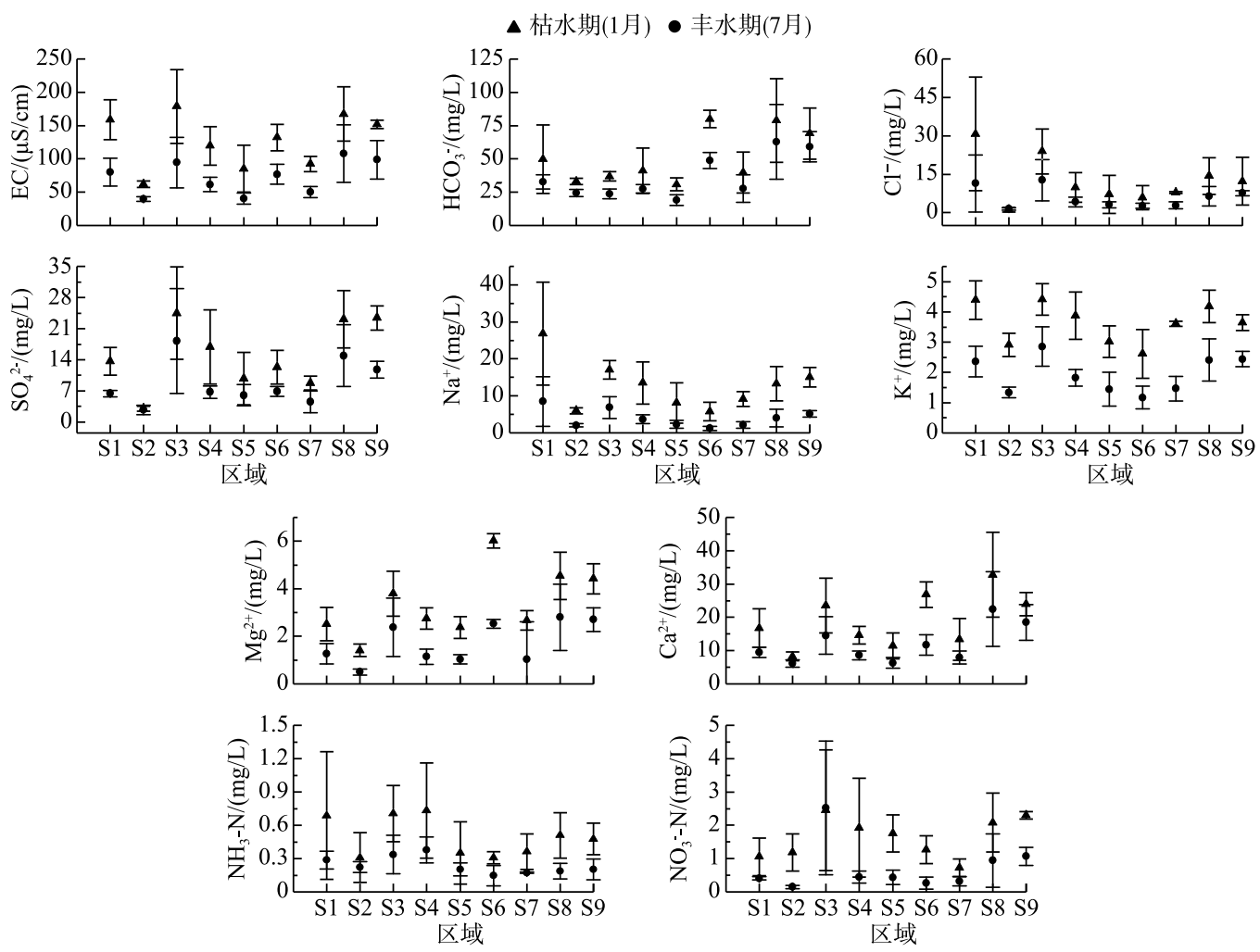

图 2 赣江水质指标时空变化特征

Fig. 2 Temporal and spatial variation characteristics of water quality parameter in Ganjiang River

\section{2 土地利用结构/景观格局变化特征}

研究区内林地面积占比最大, 平均为 $62.02 \%$, 水田所占面积比平均为 $19.72 \%$, 仅次于林地. 其次为旱 地、居民建设用地、水域、草地, 平均面积占比分别为 $9.63 \% 、 3.55 \% 、 2.61 \% 、 2.12 \%$. 从上游到下游, 水田、居民 建设用地和水域面积占比增加, 林地、草地占比下降 (图 3); $N P 、 P D 、 L S I 、 E N N \_M N 、 S H D I$ 指数不断增加, LPI、CONTAG、COHES 指数下降 (图 4), 上游地区人为干扰弱, 破碎化程度低, 景观以规则高密度的林地、草 地等斑块类型为主. 下游地区景观受人为干扰影响强烈, 景观破碎化程度增加, 水田、建设用地等土地利用 类型破坏了原有自然景观的空间分布特征, 斑块向零散不规则多边形方向发展,景观优势度降低. 
表 2 不同水情赣江水质数据描述性统计

Tab.2 Descriptive statistics of water quality data in Ganjiang River at different water conditions

\begin{tabular}{|c|c|c|c|c|c|c|c|c|}
\hline \multirow{2}{*}{ 水质指标 } & \multicolumn{2}{|c|}{ 水期 } & \multicolumn{3}{|c|}{ 河段（枯水期） } & \multicolumn{3}{|c|}{ 河段(丰水期) } \\
\hline & 枯水期 $(n=34)$ & 丰水期 $(n=34)$ & 上游 $(n=10)$ & 中游 $(n=16)$ & 下游 $(n=8)$ & 上游 $(n=10)$ & 中游 $(n=16)$ & 下游 $(n=8)$ \\
\hline $\mathrm{EC} /(\mu \mathrm{S} / \mathrm{cm})$ & $129.83 \pm 45.38^{\mathrm{a}}$ & $73.27 \pm 31.82^{b}$ & $135.68 \pm 60.41^{\mathrm{a}}$ & $110.35 \pm 29.98^{b}$ & $161.5 \pm 32.11^{\mathrm{a}}$ & $72.36 \pm 31.87^{\mathrm{b}}$ & $58.34 \pm 15.78^{\mathrm{b}}$ & $104.28 \pm 36.38^{\mathrm{a}}$ \\
\hline $\mathrm{HCO}_{3}^{-} /(\mathrm{mg} / \mathrm{L})$ & $51.51 \pm 24.78^{\mathrm{a}}$ & $36.66 \pm 19.14^{b}$ & $40.91 \pm 16.89^{b}$ & $46.25 \pm 21.21^{b}$ & $75.28 \pm 26.35^{\mathrm{a}}$ & $27.51 \pm 5.81^{\mathrm{b}}$ & $29.95 \pm 11.15^{\mathrm{b}}$ & $61.53 \pm 22.11^{\mathrm{a}}$ \\
\hline $\mathrm{Cl}^{-} /(\mathrm{mg} / \mathrm{L})$ & $12.89 \pm 12.09^{\mathrm{a}}$ & $5.82 \pm 5.56^{\mathrm{b}}$ & $19.83 \pm 18.87^{\mathrm{a}}$ & $8.21 \pm 5.13^{b}$ & $13.57 \pm 7.43^{\mathrm{a}}$ & $8.84 \pm 9.02^{\mathrm{a}}$ & $3.42 \pm 1.53^{\mathrm{b}}$ & $6.83 \pm 2.97^{\mathrm{a}}$ \\
\hline $\mathrm{SO}_{4}^{2-} /(\mathrm{mg} / \mathrm{L})$ & $15.69 \pm 8.57^{\mathrm{a}}$ & $8.74 \pm 6.18^{b}$ & $13.71 \pm 10.21^{\mathrm{b}}$ & $38.47 \pm 6.88^{\mathrm{a}}$ & $23.23 \pm 5.09^{\mathrm{b}}$ & $8.82 \pm 8.74^{\mathrm{b}}$ & $6.18 \pm 1.81^{\mathrm{b}}$ & $13.74 \pm 5.61^{\mathrm{a}}$ \\
\hline $\mathrm{Na}^{+} /(\mathrm{mg} / \mathrm{L})$ & $13.29 \pm 8.18^{\mathrm{a}}$ & $4.08 \pm 3.27^{\mathrm{b}}$ & $17.64 \pm 12.19^{\mathrm{a}}$ & $10.23 \pm 5.32^{b}$ & $13.96 \pm 3.87^{\mathrm{b}}$ & $6.05 \pm 5.01^{\mathrm{a}}$ & $2.68 \pm 1.37^{\mathrm{b}}$ & $4.43 \pm 1.96^{\mathrm{b}}$ \\
\hline $\mathrm{K}^{+} /(\mathrm{mg} / \mathrm{L})$ & $3.71 \pm 0.78^{\mathrm{a}}$ & $1.95 \pm 0.67^{\mathrm{b}}$ & $3.95 \pm 0.86$ & $3.43 \pm 0.79$ & $3.98 \pm 0.51$ & $2.21 \pm 0.76^{\mathrm{a}}$ & $1.56 \pm 0.42^{\mathrm{b}}$ & $2.42 \pm 0.54^{\mathrm{a}}$ \\
\hline $\mathrm{Mg}^{2+} /(\mathrm{mg} / \mathrm{L})$ & $3.35 \pm 1.38^{\mathrm{a}}$ & $1.69 \pm 1.1^{\mathrm{b}}$ & $2.57 \pm 1.15^{\mathrm{b}}$ & $3.27 \pm 1.41^{\mathrm{b}}$ & $4.49 \pm 0.82^{\mathrm{a}}$ & $1.37 \pm 1.01^{\mathrm{b}}$ & $1.36 \pm 0.84^{\mathrm{b}}$ & $2.76 \pm 1.08^{\mathrm{a}}$ \\
\hline $\mathrm{Ca}^{2+} /(\mathrm{mg} / \mathrm{L})$ & $19.27 \pm 9.72^{\mathrm{a}}$ & $11.93 \pm 7.23^{b}$ & $16.23 \pm 8.08^{\mathrm{b}}$ & $16.08 \pm 6.47^{b}$ & $29.46 \pm 10.81^{\mathrm{a}}$ & $9.97 \pm 4.51^{\mathrm{b}}$ & $8.63 \pm 2.40^{\mathrm{b}}$ & $20.97 \pm 9.18^{\mathrm{a}}$ \\
\hline $\mathrm{NH}_{3}-\mathrm{N} /(\mathrm{mg} / \mathrm{L})$ & $0.52 \pm 0.33^{\mathrm{a}}$ & $0.25 \pm 0.11^{\mathrm{b}}$ & $0.58 \pm 0.41$ & $0.51 \pm 0.35$ & $0.49 \pm 0.17$ & $0.28 \pm 0.11^{\mathrm{a}}$ & $0.26 \pm 0.13^{\mathrm{a}}$ & $0.19 \pm 0.07^{\mathrm{b}}$ \\
\hline $\mathrm{NO}_{3}^{-}-\mathrm{N} /(\mathrm{mg} / \mathrm{L})$ & $1.68 \pm 1.03^{\mathrm{a}}$ & $0.719 \pm 0.88^{b}$ & $1.51 \pm 1.15$ & $1.54 \pm 1.08$ & $2.16 \pm 0.68$ & $0.99 \pm 1.46^{\mathrm{a}}$ & $0.39 \pm 0.17^{\mathrm{b}}$ & $1.01 \pm 0.62^{\mathrm{a}}$ \\
\hline
\end{tabular}

“ $n$ ”代表采样点数量, 不同水期和河段不同字母表示水化学指标差异显著 $(P<0.05)$.

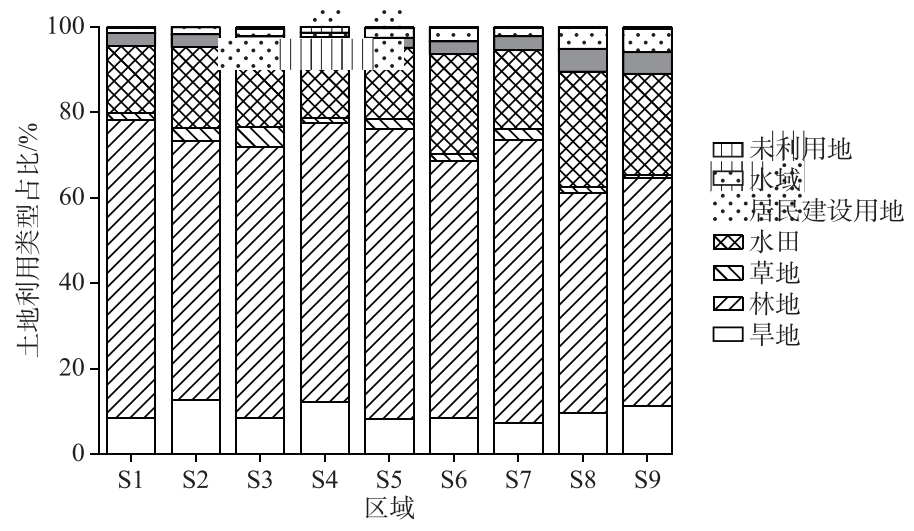

图 3 不同区域土地利用特征

Fig.3 Land use characteristics in different regions

\section{3 土地利用结构/景观格局与水质的相关分析}

居民建设用地与所有水质指标都呈正相关, 且枯水期与 $\mathrm{Ca}^{2+} 、 \mathrm{NO}_{3}^{-}-\mathrm{N}$ 浓度的相关性显著, 丰水期与 $\mathrm{EC} 、$ $\mathrm{HCO}_{3}^{-} 、 \mathrm{SO}_{4}^{2-} 、 \mathrm{Ca}^{2+} 、 \mathrm{Mg}^{2+}$ 的相关性显著. 水田和水域与 $\mathrm{HCO}_{3}^{-} 、 \mathrm{Ca}^{2+} 、 \mathrm{Mg}^{2+}$ 浓度呈显著正相关. 林地和草地与水 质指标大多呈负相关, 其中林地与 $\mathrm{HCO}_{3}^{-}$浓度呈显著负相关 $(P<0.05)$, 在丰水期相关性加强. 而草地与 $\mathrm{NO}_{3}^{-}-\mathrm{N} 、 \mathrm{NH}_{3}-\mathrm{N}$ 浓度呈正相关, 但未达到显著性程度.

$E N N \_M N$ 指数与所有水质指标呈正相关, 并在丰水期与 $\mathrm{Ca}^{2+} 、 \mathrm{HCO}_{3}^{-}$浓度达到显著性水平. 枯水期景观 指数与所有水质指标相关性均不显著 (图 5), COHES 指数与 $\mathrm{Ca}^{2+} 、 \mathrm{HCO}_{3}^{-}$浓度在丰水期达到显著负相关. CONTAG、COHES 指数与 $\mathrm{NH}_{3}-\mathrm{N}$ 浓度都呈正相关, 与其余水质指标呈负相关, $L P I 、 N P 、 P D 、 L S I$ 和 SHDI 指数 都与 $\mathrm{HCO}_{3}^{-} 、 \mathrm{SO}_{4}^{2-} 、 \mathrm{Cl}^{-}$浓度呈正相关. 可见 CONTAG、COHES、ENN_MN 指数对水质变化影响显著.

林地与表征景观聚集度的 COHES、CONTAG 指数呈正相关, 与 $L P I 、 N P 、 P D 、 L S I$ 和 SHDI、ENN_MN 指数 均呈负相关. 建设用地、水田与表征景观破碎度的 NP、PD、LSI 指数呈负相关. 可见土地利用结构与景观格 局之间存在交互影响.

根据“bioenv” 分析结果 (表 3) 表明, 水田、林地和建设用地的组合与水质的相关系数最高, 在枯水期和 丰水期分别为 0.1575 和 0.5251 . 枯水期 $N P$ 指数与 $E N N \_M N$ 指数组合相关系数最高达 0.1838 , 丰水期 

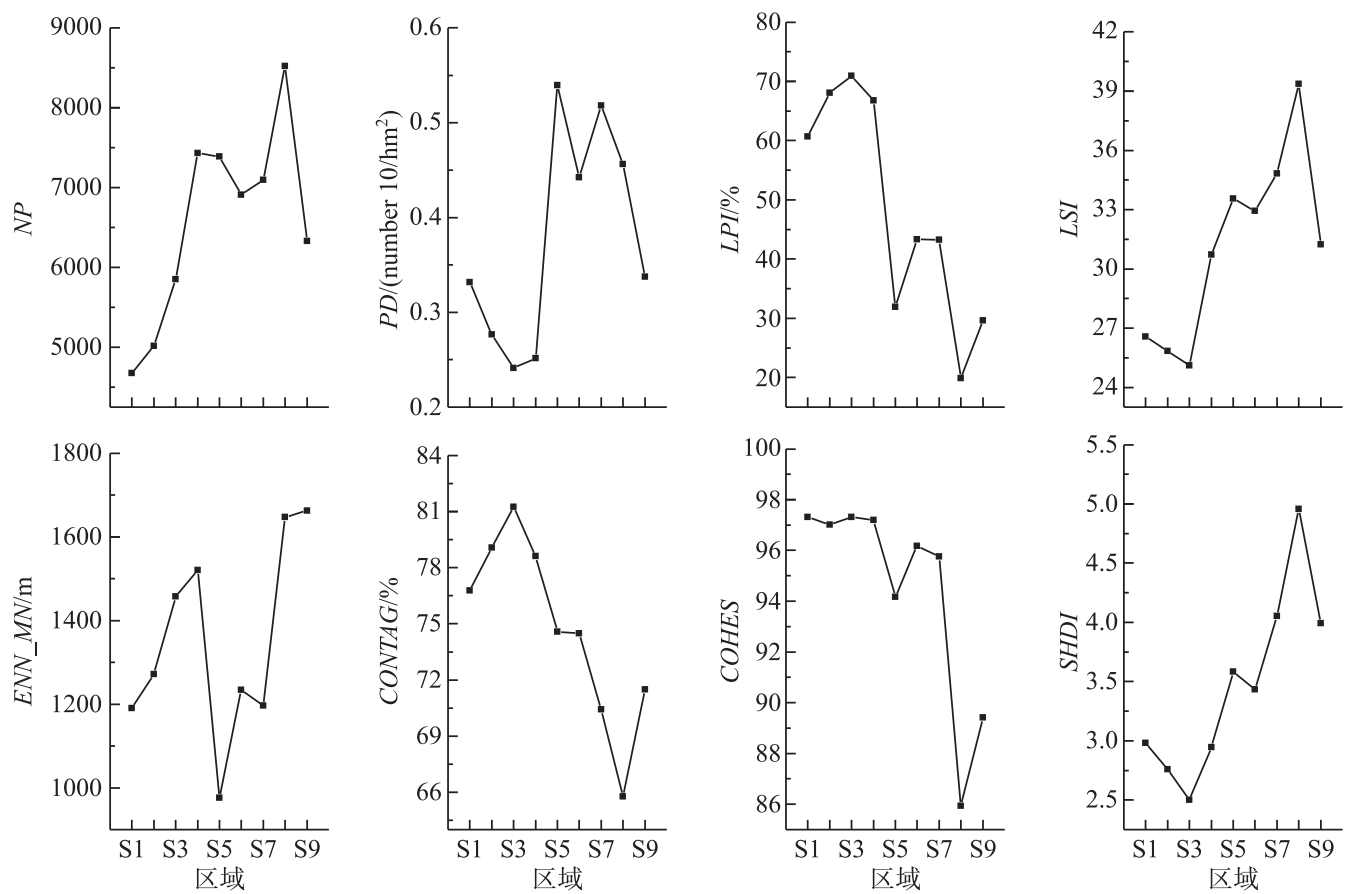

图 4 赣江流域景观指数变化特征

Fig.4 The change characteristics of landscape indexes in Ganjiang River Basin

COHES 指数与 ENN_MN 指数相关系数达 0.4219. 为减少指标间的信息冗余,获取土地利用结构与景观格局 对水质准确的贡献率, 降低不同指标组合存在的差异. 采用水田、林地和建设用地的组合代表土地利用结 构, $N P 、 E N N \_M N$ 指数的组合与 COHES、ENN_MN 指数的组合分别表征流域枯水期和丰水期的景观格局.

(a)

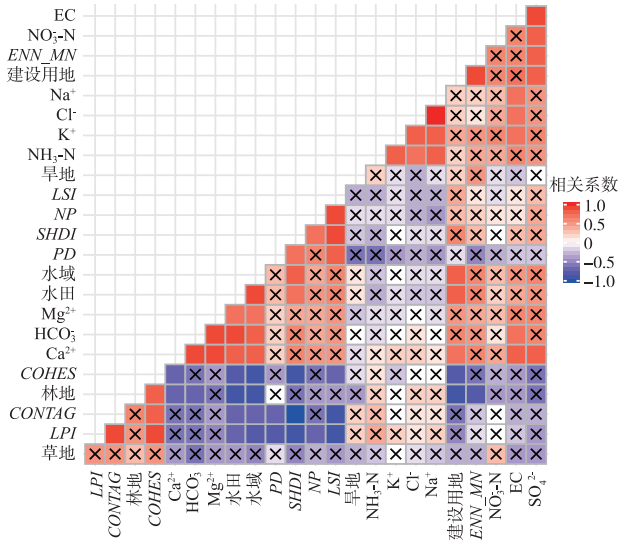

(b)

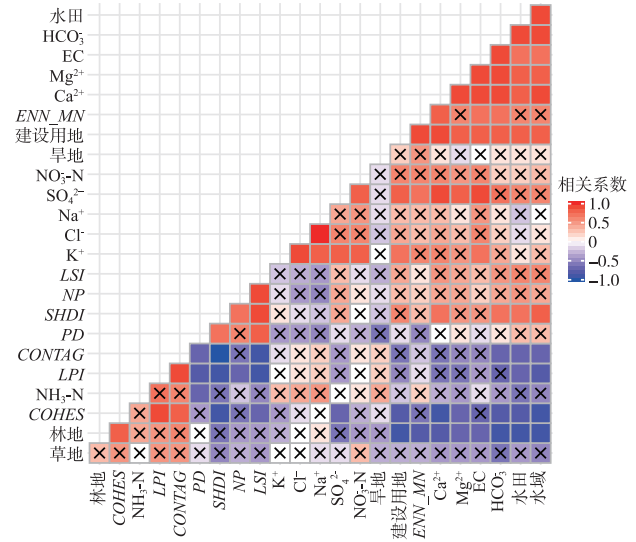

图 5 丰水期 ( a )、枯水期 (b) 水质指标与土地利用结构/景观指数的相关性

(“×”表示相关性不显著 $(P>0.05)$ )

Fig.5 Correlation between water quality index and land use structure/landscape indexes during wet (a) and dry (b) seasons 
表 3 赣江水质与土地利用结构和景观指数组合的相关关系

Tab.3 Correlation between combinations of land use structure and landscape indexes with water quality in Ganjiang River

\begin{tabular}{|c|c|c|c|c|}
\hline & 水质与土地利用类型 & 相关系数 & 水质与景观指数 & 相关系数 \\
\hline \multirow[t]{6}{*}{ 枯水期 } & 水田 & 0.1534 & $N P$ & 0.0927 \\
\hline & 林地+水田 & 0.1287 & $N P+E N N \_M N$ & 0.1838 \\
\hline & 林地+水田+建设用地 & 0.1575 & $N P+P D+E N N \_M N$ & 0.1650 \\
\hline & 林地+水田+建设用地+水域 & 0.1418 & $N P+P D+L P I+E N N \_M N$ & 0.1493 \\
\hline & 旱地+林地+水田+建设用地+水域 & 0.0770 & $N P+P D+L P I+L S I+E N N \_M N$ & 0.1223 \\
\hline & 旱地+林地+草地+水田+建设用地+水域 & 0.0075 & $N P+P D+L P I+L S I+E N N \_M N+S H D I$ & 0.0924 \\
\hline \multirow[t]{6}{*}{ 丰水期 } & 建设用地 & 0.4712 & COHES & 0.4093 \\
\hline & 建设用地+水域 & 0.5251 & ENN_MN+COHES & 0.4219 \\
\hline & 林地+水田+建设用地 & 0.5251 & $L P I+E N N \_M N+C O H E S$ & 0.4232 \\
\hline & 林地+水田+建设用地+水域 & 0.5250 & $L P I+L S I+E N N \_M N+C O H E S$ & 0.3936 \\
\hline & 林地+草地+水田+建设用地+水域 & 0.4690 & $N P+L P I+L S I+E N N \_M N+C O H E S$ & 0.3583 \\
\hline & 旱地+林地+草地+水田+建设用地+水域 & 0.3768 & $N P+L P I+L S I+E N N \_M N+S H D I+C O H E S$ & 0.3274 \\
\hline
\end{tabular}

* 水质与景观指数的组合只选取了相关系数最高的 6 组.

\section{4 土地利用结构/景观格局对水质的交互影响}

Mentel test 结果表明 (表 4), 枯水期景观格局、土地利用结构与水质的相关性都很低, 且均不显著. 丰水 期与此相反且二者与水质的相关性都达到显著水平 $(P<0.05)$. Partial Mantel test 结果 (表 4) 表明, 在控制 土地利用结构和景观格局之间的相互影响之后, 土地利用结构、景观格局与水质的相关性都出现下降, 其中 土地利用结构与水质的相关性在枯水期下降了 0.012 , 在丰水期, 下降了 0.236 . 景观格局与水质的相关性在 枯水期下降了 0.008 ,而在丰水期下降了 0.158 后相关性仍显著.

方差分解结果 (图 6) 表明土地利用结构与景观格局对水质的交互作用在丰水期最高. 枯水期土地利用 结构单独解释了 $23.9 \%$ 的水质变化, 景观格局无单独解释变量. 共同作用部分为 $17.2 \%$, 分别占土地利用结 构总贡献率的 $41.8 \%$, 景观格局总贡献率的 100\% . 丰水期土地利用结构与景观格局单独解释为 $14 \%$ 和 $16 \%$ 的水质变化. 共同作用部分达到 $37 \%$, 分别占土地利用结构总贡献率的 $72.5 \%$, 景观格局总贡献率的 $69.8 \%$. 可见土地利用结构与景观格局的交互作用是水质变化的重要因素, 在丰水期贡献率最高.

表 4 土地利用和景观格局与水质的 Mantel 检验

Tab.4 Mantel test between land use structure and landscape pattern with water quality

\begin{tabular}{ccccccc}
\hline \multirow{2}{*}{ 水期 } & & \multicolumn{2}{c}{ Mantel test } & & \multicolumn{2}{c}{ Partial Mantel test } \\
\cline { 3 - 4 } \cline { 5 - 6 } & & 相关性 $(r)$ & 显著性 $(P)$ & & 相关性 $(r)$ & 显著性 $(P)$ \\
\hline 枯水期 & 土地利用结构 & 0.063 & 0.332 & & 0.051 & 0.419 \\
& 景观格局 & 0.091 & 0.311 & & 0.083 & 0.283 \\
丰水期 & 土地利用结构 & 0.550 & $\mathbf{0 . 0 1 1}$ & & 0.314 & 0.060 \\
& 景观格局 & 0.479 & $\mathbf{0 . 0 1 3}$ & & 0.321 & $\mathbf{0 . 0 4 8}$ \\
\hline
\end{tabular}

\section{3 讨论}

本研究发现,枯水期交互作用占土地利用结构总贡献率的 $41.8 \%$, 景观格局的总贡献率完全为与土地利 用结构的交互作用; 丰水期土地利用结构与景观格局对水质的交互作用分别占各自总贡献率的 $72.5 \%$ 和 $69.8 \%$. 已有研究表明水体污染物一半以上通过径流汇人河流, 流域内径流补给深刻影响河流水质 ${ }^{[28-29]}$. 而 产汇流过程受到土地利用结构与景观格局交互作用影响 ${ }^{[30-31]}$. 通过模拟降雨实验发现, 降雨强度、前期土壤 含水量、土壤物理特征、植被占比, 是影响产流过程的主要因素 ${ }^{[32]}$, 其中土壤物理特征, 包括饱和土壤含水 


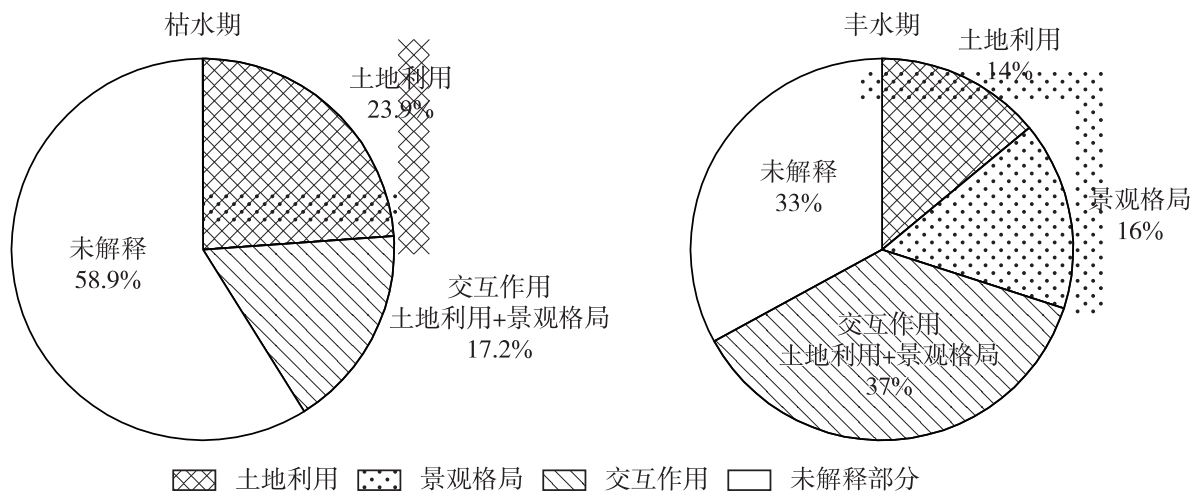

图 6 土地利用结构与景观格局对水质的贡献率

Fig. 6 The contribution rate of land use structure and landscape pattern to water quality

量、粒度、孔隙度等, 会直接影响水体下渗能力以及壤中流产流机制 ${ }^{[30]}$; 低植被占比会减少植被截留量, 导致 径流的速度和体积明显增加 ${ }^{[28]}$. 前期土壤含水量、土壤物理特征、植被占比等因素直接影响产流过程, 且土 地利用作为污染物的“源”和“汇”直接导致不同土地利用类型产出径流水质不同 ${ }^{[33]}$. 已有研究表明景观格 局在汇流过程中对水质作用显著 ${ }^{[34-35]}$, 在径流汇人河网的过程中自然景观类型起过滤作用,如林地、草地可 以截取进人水体中的泥沙、重金属、有机质等污染物 ${ }^{[34]}$. 而水田、建设用地等人工景观类型在径流汇流过程 中富集了污染物 ${ }^{[66-37]}$. 土壤是地表污染物主要附着的载体, 在水体下渗形成壤中流过程中冲刷、溶解土壤表 面污染物质,壤中流在流动过程受到林地等自然景观的截留作用, 污染物随之被吸收固定, 在流经建设用地 等人工景观过程中受到下垫面差异影响,被迫改道或转变为地表径流,污染物随之汇人径流或在原地固结 堆积 ${ }^{[32,36]}$. 汇流过程中流经的景观类型越多, 水质变化越大 ${ }^{[34]}$, 最终富集或是稀释径流中污染物的浓 度 ${ }^{[7,30]}$. 建设用地等 “源” 景观斑块的优势度和自然连通性较高, 当流域景观格局主要由少数聚集的较大 “源” 斑块组成时, 会沟通空间上原本分散分布的污染物, 为其远距离扩散和集中输出提供通道, 相对弱化了 “汇” 景观斑块对污染物的截留和削减效应, 加剧了“源” 景观对水质的威胁程度 ${ }^{[30-32]}$. 同时, 当流域景观格 局的破碎化程度越高、景观类型多样性越低,景观异质性下降时, “源” 景观向周围景观输出污染物质的几率 可能增加, “汇” 景观在涵养水源和保持水土方面的作用会随之下降 ${ }^{[33-35]}$, 因此赣江流域土地利用结构与景 观格局的交互作用是水质变化的重要原因,在土地利用结构与景观格局分别对水质的总贡献率中占有较高 比例. 图 6 中水质变化的未解释部分可能是未考虑土壤性质差异造成的,已有研究表明, 即使是相同土地利 用类型不同的土壤特征也会对径流形成产生较大影响, 尤其对壤中流的产流机制影响巨大 ${ }^{[37]}$, 此外不同土 地利用类型的相邻区域受到周边多种土地利用共同作用, 对污染物的源汇机制难以分析, 可能是未解释部 分的来源之一.

本次研究发现, 土地利用结构与景观格局对水质的影响在枯水期小于丰水期,景观格局的影响在枯水 期的下降更明显. 模拟降雨实验表明,降雨强度与前期土壤含水量越高越有利于地表径流的形成和养分的 输出 ${ }^{[36]}$. 赣江流域 11 一次年 1 月降水量占全年的 $16.8 \%, 5-7$ 月降水量占全年的 $45.6 \%{ }^{[23]}$, 丰水期长时间 高强度的降水使土壤前期含水量维持在较高水平, 有利于径流形成 ${ }^{[35]}$, 而枯水期与此相反, 因此土地利用结 构与景观格局在丰水期对水质的影响更高, 且景观格局主要在汇流过程中影响水质 ${ }^{[34-35]}$, 赣江流域枯水期 降水较少, 汇流过程不显著, 景观格局对水质的影响完全涵盖在与土地利用结构的交互作用中 ${ }^{[38]}$, 因而下降 显著. 坡度作为影响径流形成的原因之一, 在较高的坡度条件下会加速径流的形成, 提升对地表的冲刷能力 导致污染物浓度增加 ${ }^{[39]}$, 而不同坡度大小上土地利用结构能较好地反映人类活动强度, 低坡度区域由于人 类活动强度较大对污染物浓度具有较大的影响 ${ }^{[39]}$, 赣江下游较低的坡度适宜人类活动, 可能是导致污染物 浓度增加的重要原因.

研究结果表明, 土地利用类型中林地、水田、居民建设用地, 对 $\mathrm{EC} 、 \mathrm{HCO}_{3}^{-} 、 \mathrm{SO}_{4}^{2-} 、 \mathrm{Ca}^{2+} 、 \mathrm{Mg}^{2+} 、 \mathrm{NO}_{3}^{-}-\mathrm{N}$ 等水 
质指标影响显著. 林地通过截留、吸收污染物净化水质, 对污染物起 “汇” 作用 ${ }^{[4]}$, 与 $\mathrm{HCO}_{3}^{-}$浓度呈显著负相 关 (图 5). 水田因农田退水影响而成为流域非点源污染的主要来源 ${ }^{[21]}$, 与 $\mathrm{HCO}_{3}^{-} 、 \mathrm{Ca}^{2+} 、 \mathrm{Mg}^{2+}$ 等水质指标呈显 著正相关 (图 5). 建设用地是人类对自然干扰最强烈的土地利用方式, 是流域点源污染的主要来源 ${ }^{[40-41]}$, 与 $\mathrm{EC} 、 \mathrm{HCO}_{3}^{-} 、 \mathrm{SO}_{4}^{2-} 、 \mathrm{Ca}^{2+} 、 \mathrm{Mg}^{2+}$ 等水质指标呈显著正相关(图 5). 林地、水田、居民建设用地等景观类型不同的 “源” “汇”功能影响了水质指标浓度. 此外, 桃江流域的信丰县盛产脐橙, 是国家商品粮基地县, Z9 点 $\mathrm{NH}_{3}-\mathrm{N} 、 \mathrm{NO}_{3}^{-}-\mathrm{N}$ 等指标浓度均异常超标可能是受到当地农业用地过量施肥的影响. 研究区草地与 $\mathrm{NH}_{3}-\mathrm{N}$ 、 $\mathrm{NO}_{3}^{-}-\mathrm{N}$ 浓度呈正相关, 原因可能与研究区草地面积平均占比较小有关, 受到草地周边农田、建设用地取代自 然景观用地的影响,增加了污染物的总量, 减弱了自然植被对污染物的截留、吸收作用 ${ }^{[42-43]}$, 掩盖了草地与 水质间的关系,与浑太河、东江河流域研究相似 ${ }^{[44-45]}$.

本次研究发现, NP、ENN_MN、COHES 指数对水质影响显著, CONTAG、LPI、PD、LSI 和 SHDI 指数与水质 相关性不强. 较高的 NP、ENN_MN 指数提高了汇流过程中经过多种景观类型的概率, 较低的 COHES 指数影 响下, 林地等对水质具有净化作用的土地利用类型呈现零散不规则的斑块分布, 无法有效净化水质 ${ }^{[8,12]}$. 因 此 $N P 、 E N N \_M N 、 C O H E S$ 指数与水质有较高的相关性. 已有研究表明 ${ }^{[42,46]}, 4 \mathrm{~km}$ 缓冲区尺度景观指数对水 质解释能力最强, 其中 $P D$ 指数在 $100 \mathrm{~m}$ 缓冲区影响显著, $L P I 、 L S I$ 指数在 $300 \mathrm{~m}$ 缓冲区与水质相关性最高, $S H D I$ 指数无论是全流域尺度还是缓冲区尺度都是水质的重要预测因子. 故 CONTAG、LPI、PD、LSI 和 SHDI 等指数与水质相关性较弱可能是受到研究区区域划分的影响 ${ }^{[43-45]}$. 因此赣江流域不同空间尺度下景观格局 对水质的影响仍需深人研究.

\section{4 结论}

1) 赣江流域丰水期水质指标浓度显著低于枯水期, 水体阳离子浓度 $\mathrm{Ca}^{2+}>\mathrm{Na}^{+}>\mathrm{K}^{+}>\mathrm{Mg}^{2+}$, 阴离子浓度 $\mathrm{HCO}_{3}^{-}>\mathrm{SO}_{4}^{2-}>\mathrm{Cl}^{-}$. 上游和中游水质指标差异性不显著, 下游 $\mathrm{EC} 、 \mathrm{HCO}_{3}^{-} 、 \mathrm{SO}_{4}^{2-} 、 \mathrm{Mg}^{2+} 、 \mathrm{Ca}^{2+} 、 \mathrm{NO}_{3}^{-}-\mathrm{N}$ 等水质指标 浓度最高.

2) 林地、水田、建设用地的组合; $N P 、 E N N \_M N 、 C O H E S$ 指数的组合与水质相关性最高, 建设用地与 $E N N \_M N$ 指数以及所有水质指标呈正相关, 是预测水质变化的关键指标.

3) 土地利用结构与景观格局对水质有较大影响, 枯水期贡献率分别为 $41.1 \%$ 和 $17.2 \%$, 丰水期贡献率分 别为 $51 \%$ 和 $53 \%$,其中景观格局的影响在枯水期完全涵盖在与土地利用结构的交互作用中.

4) 土地利用结构与景观格局的交互作用是影响赣江流域水质的重要方式,在土地利用结构与景观格局 对水质的总贡献率中占较高比例,枯水期分别占 $41.8 \%$ 和 $100 \%$, 丰水期分别占 $72.5 \%$ 和 $69.8 \%$.

\section{5 参考文献}

[ 1 ] Huang J, Li Q, Pontius RG et al. Detecting the dynamic linkage between landscape characteristics and water quality in a subtropical coastal watershed, southeast China. Environmental Management, 2013, 51(1) : 32-44.

[ 2 ] Zhu ZX, Gao XF, Peng F et al. Relationship between water quality and landscape characteristics of the Houxi river watershed in Xiamen City along a rural-urban gradient. Acta Ecologica Sinica, 2019, 39(6) : 2021-2033. [朱珍香, 高肖飞, 彭凤等. 厦门后溪水质与流域景观特征沿城乡梯度的变化分析. 生态学报, 2019, 39(6): 2021-2033.]

[ 3 ] Tu J. Spatially varying relationships between land use and water quality across an urbanization gradient explored by geographically weighted regression. Applied Geography, 2011, 31(1): 376-392.

[ 4 ] Chen LD, Fu BJ, Zhao WW. Source-sink landscape theory and its ecological significance. Acta Ecologica Sinica, 2006, 26 (5) : 1444-1449. [陈利顶, 傅伯杰, 赵文武. “源” “汇” 景观理论及其生态学意义. 生态学报, 2006, 26 ( 5)： $1444-1449$.

[ 5 ] Wu J. Effects of changing scale on landscape pattern analysis: scaling relations. Landscape Ecology, 2004, 19(2): 125-138.

[ 6 ] Zhang DW, Li YF, Sun X et al. Relationship between landscape pattern and river water quality in Wujingang region, Taihu lake watershed. Environmental Science, 2010, 31(8): 1775-1783. [张大伟, 李杨帆, 孙翔等. 人太湖河流武进 港的区域景观格局与河流水质相关性分析. 环境科学, 2010, 31(8): 1775-1783.]

[ 7 ] Wang J, Li P, Gao HD et al. Preliminary study on the relationship between land use/landscape index and water quality in 
the upper reaches of Dangjiang River. Research of Soil and Water Conservation, 2018, 25(6) : 383-389. [王杰, 李鹏, 高 海东等. 丹江上游土地利用/景观指数与水质关系初探. 水土保持研究, 2018, 25(6) : 383-389.]

[ 8 ] Wang XP, Zhang F, Li XH et al. Correlation analysis between the spatial characteristics of land use/cover-landscape pattern and surface-water quality in the Ebinur Lake area. Acta Ecologica Sinica, 2017, 37(22): 7438-7452. [王小平, 张 飞, 李晓航等. 艾比湖区域景观格局空间特征与地表水质的关联分析. 生态学报, 2017, 37(22): 7438-7452.]

[ 9 ] Yu SY, Xu ZX, Wu W et al. Spatial variation of water quality and its response to land use in the Beiluo River basin. Acta Scientiae Circumstantiae, 2014, 34(5)：1309-1315. [于松延, 徐宗学, 武玮等. 北洛河流域水质空间异质性及其对 土地利用结构的响应. 环境科学学报, 2014, 34(5): 1309-1315.]

[10] Amiri BJ, Nakane K. Modeling the linkage between river water quality and landscape metrics in the Chugoku District of Japan. Water Resources Management, 2009, 23(5) : 931-956.

[11] Zhao P, Xia BC, Qin JQ et al. Multivariate correlation analysis between landscape pattern and water quality. Acta Ecologica Sinica, 2012, 32(8) : 2331-2341. [ 赵鹏, 夏北成, 秦建桥等. 流域景观格局与河流水质的多变量相关分析. 生 态学报, 2012, 32(8): 2331-2341.]

[12] Bu H, Meng W, Zhang Y et al. Relationships between land use patterns and water quality in the Taizi River basin, China. Ecological Indicators, 2014, 41: 187-197.

[13] Hao ZC, Su ZK. Effects of land use change on runoff in the typical areas in Haihe River basin. Advances in Water Science, 2015, 26(4) : 491-499. [郝振纯, 苏振宽. 土地利用变化对海河流域典型区域的径流影响. 水科学进展, 2015, 26 (4) : 491-499.]

[14] Li MT, Wang XY, Liu WZ. Relationship between landscape pattern and non-point source pollution loads in the Chaohe River Watershed. Acta Scientiae Circumstantiae, 2013, 33(8): 2296-2306. [李明涛, 王晓燕, 刘文竹. 潮河流域景观 格局与非点源污染负荷关系研究. 环境科学学报, 2013, 33(8): 2296-2306.]

[15] Cui D, Chen Y, Ma BR et al. Effects of land use/landscape patterns on the water quality. Advances in Water Science, $2019,30(3)$ : 1-11. [崔丹, 陈岩, 马冰然等. 土地利用/景观格局对水环境质量的影响. 水科学进展, 2019, 30 (3) : $1-11$.

[16] Liu J, Fu PP. Analyses of application traps of SEM. Application of Statistics and Management, 2007, (2) : 268-272. [刘] 军, 富萍萍. 结构方程模型应用陷阱分析. 数理统计与管理, 2007, (2) : 268-272.]

[17] Chen L, Tian H, Fu B et al. Development of a new index for integrating landscape patterns with ecological processes at watershed scale. Chinese Geographical Science, 2009, 19(1) : 37-45.

[18] Xiao R, Wang G, Zhang Q et al. Multi-scale analysis of relationship between landscape pattern and urban river water quality in different seasons. Sci Rep, 2016, 6: 25250.

[19] Wang ML, Zhou WB, Hu CH. The distribution characteristics of various firms of nitrogen and phosphorus in the Ganjiang catchment during dry season. Earth and Environment, 2007, (2) : 166-170. [王毛兰, 周文斌, 胡春华. 枯水期赣江流 域氮磷的分布特征. 地球与环境, 2007, (2): 166-170.]

[20] Wang P, Qi SH, Chen B. Influence of land use on river water quality in the Ganjiang Basin. Acta Ecologica Sinica, 2015, 35(13) : 4326-4337. [王鹏, 齐述华, 陈波. 赣江流域土地利用方式对河流水质的影响. 生态学报, 2015, 35(13): 4326-4337. ]

[21] Wang P, Qi SH, Yuan RQ. Investigation of the impacts of land use on inorganic nitrogen in the Ganjiang River. Acta Scientiae Circumstantiae, 2015, 35(3):826-835. [王鹏, 齐述华, 袁瑞强. 赣江流域土地利用方式对无机氮的影响. 环 境科学学报, 2015, 35(3): 826-835.]

[22] Zhao J, Wang P, Yu XF. The effect of land use patterns on stream water nitrogen and phosphorus nutrients under the variations of temperature and precipitation in Ganjiang River basin. Journal of Jiangxi Normal University: Natural Science, 2018, 42(6): 655-660. [ 赵君, 王鹏, 余小芳. 温度和降水对赣江流域土地利用方式与河流氮磷营养盐相关性的 影响. 江西师范大学学报: 自然科学版, 2018, 42(6) : 655-660.]

[23] Liu QJ, Liu XD. Discussion of the variation law of low water level on Nanchang reach of Ganjiang River. Jiangxi Hydraulic Science \& Technology, 2010, 36(1) : 51-55. [刘琦俊, 刘小东. 赣江南昌河段枯水位变化规律探讨. 江西水利科技, $2010,36(1): 51-55$.

[24] Bu RC, Hu YM, Chang Y et al. A correlation analysis on landscape metrics. Acta Ecologica Sinica, 2005, (10): 27642775. [布仁仓, 胡远满，常禹等. 景观指数之间的相关分析. 生态学报, 2005，(10): 2764-2775.]

[25] Huang JL, Li QS, Hong HS et al. Preliminary study on linking land use \& landscape pattern and water quality in the Jiu- 
long River watershed. Environmental Science, 2011, 32(1):64-72. [黄金良, 李青生, 洪华生等. 九龙江流域土地利 用/景观格局-水质的初步关联分析. 环境科学, 2011, 32(1): 64-72.]

[26] Borcard DP, Legendre P, Drapeau P. Partialling out the spatial component of ecological variation. Ecology, 1992, 73 (3) : 1045-1055.

[27] Økland RH, Eilertsen O. Canonical Correspondence Analysis with variation partitioning: some comments and an application. Journal of Vegetation Science, 1994, 5(1): 117-126.

[28] Zhang GL, Liu GB, Wang GL et al. Effects of vegetation cover and rainfall intensity on sediment-bound nutrient loss, size composition and volume fractal dimension of sediment particles. Pedosphere, 2011, 21(5) : 676-684.

[29] Zheng Y, Wang XJ. Advances and prospects for nonpoint source pollution studies. Advances in Water Science, 2002, (1): 105-110. [郑一, 王学军. 非点源污染研究的进展与展望. 水科学进展, 2002, (1) : 105-110. ]

[30] Ouyang W, Skidmore AK, Toxopeus AG et al. Long-term vegetation landscape pattern with non-point source nutrient pollution in upper stream of Yellow River basin. Journal of Hydrology, 2010, 389(3/4) : 373-380.

[31] Jiang Y, Xie Z, Zhang H et al. Effects of land use types on dissolved trace metal concentrations in the Le'an River Basin, China. Environmental Monitoring and Assessment, 2017, 189(12).

[32] Liu R, Wang J, Shi J et al. Runoff characteristics and nutrient loss mechanism from plain farmland under simulated rainfall conditions. Science of the Total Environment, 2014, 468/469: 1069-1077.

[33] Germer S, Neill C, Krusche AV et al. Influence of land-use change on near-surface hydrological processes: Undisturbed forest to pasture. Journal of Hydrology, 2010, 380(3/4) : 473-480.

[34] Zhang X, Luo Y, Goh KS. Modeling spray drift and runoff-related inputs of pesticides to receiving water. Environmental Pollution, 2018, 234: 48-58.

[35] Pan Z, Sun ZY, Ma R et al. Isotopic investigation of rainfall-runoff generation in an alpine catchment in headwater regions of HeiHe River, northeast Qinghai-Tibet Plateau. Earth Science, 2018, 43(11): 4226-4236. [潘钊, 孙自永, 马瑞等. 黑河上游高寒山区降雨-径流形成过程的同位素示踪. 地球科学, 2018, 43(11): 4226-4236.]

[36] Shigaki F, Sharpley A, Prochnow LI. Rainfall intensity and phosphorus source effects on phosphorus transport in surface runoff from soil trays. Science of the Total Environment, 2007, 373(1) : 334-343.

[37] Li C, Zhang Y, Kharel G et al. Impact of climate variability and landscape patterns on water budget and nutrient loads in a peri-urban watershed: A coupled analysis using process-based hydrological model and landscape indices. Environmental Management, 2018, 61(6) : 954-967.

[38 Chen CC, Zhang YQ, Xiang Y et al. Study on runoff responses to land use change in Ganjiang Basin. Journal of Natural Resources, 2014, 29(10): 1758-1769. [ 陈昌春, 张余庆, 项瑛等. 土地利用变化对赣江流域径流的影响研究. 自然 资源学报, 2014, 29(10): 1758-1769.]

[39] Jiang YH, Xie ZL, Zhang H et al. Effect of land use structure and social economy on concentrations of dissolved heavy metal in Ganjiang River Basin. Acta Scientiae Circumstantiae, 2017, 37(7) : 2531-2542. [江英辉, 谢正碟, 张华等. 竷 江流域土地利用结构及社会经济对河流可溶性重金属含量的影响. 环境科学学报, 2017, 37(7): 2531-2542.]

[40] Sun QQ, Huang JL, Hong HS et al. Study on the linkage between urban built-up land and water quality in the Jiulong River Watershed. Environmental Science, 2011, 32(10): 2849-2854. [孙芹芹, 黄金良, 洪华生等. 九龙江流域城镇建设 用地与河流水质关系研究. 环境科学, 2011, 32(10): 2849-2854.]

[41] Li S, Xia X, Tan X et al. Effects of catchment and riparian landscape setting on water chemistry and seasonal evolution of water quality in the upper Han River Basin, China. PLoS ONE, 2013, 8(1) : e53163.

[42] Pratt B, Chang H. Effects of land cover, topography, and built structure on seasonal water quality at multiple spatial scales. Journal of Hazardous Materials, 2012, 209/210: 48-58.

[43] Zhou T, Wu J, Peng S. Assessing the effects of landscape pattern on river water quality at multiple scales: A case study of the Dongjiang River watershed, China. Ecological Indicators, 2012, 23: 166-175.

[44] Li YL, Xu ZX, Li YF. A preliminary study on the relationship between multi-scale land use and landscape and river water quality response in the Huntai watershed. Earth and Environment, 2012, 40(4): 573-583. [李艳利, 徐宗学, 李艳粉. 浑太河流域多尺度土地利用/景观格局与水质响应关系初步分析. 地球与环境, 2012, 40(4): 573-583.]

[45] Cao C, Zhang F, Ayinigeer $\cdot$ Yalikun et al. Relationship between landscape pattern and water quality in the Ebinur Lake region. Environmental Science, 2018, 39(4): 1568-1577. [曹灿, 张飞, 依尼格尔·亚力坤等. 艾比湖区域景观格局与 河流水质关系探讨. 环境科学, 2018, 39(4) : 1568-1577. 